\title{
Treatment Outcomes of Patients with Multidrug-Resistant Tuberculosis: Concern to Bedaquiline
}

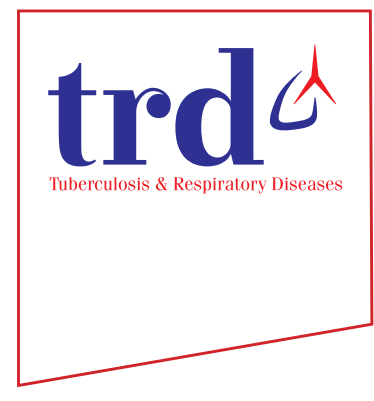

\author{
Oki Nugraha Putra, M.Clin.Pharm. and Affan Y. N. Hidayatullah, B.Pharm. \\ Department of Clinical Pharmacy, Program Study of Pharmacy, Hang Tuah University, Surabaya, East Java, Indonesia
}

We greatly appreciated the study by Kang et al. ${ }^{1}$, which reported successful treatment outcomes and fewer cases lost to follow-up after implementing the public-private mixing period. The data were collected retrospectively over ten years. As we know, multidrug-resistant tuberculosis (MDR-TB) is still a complicated problem worldwide with a high level of treatment failure and mortality, including in Indonesia due to poor adherence and several adverse effects of the drugs. Kang et al. ${ }^{1}$, also reported that MDR-TB patients with age older than 65 years old, low body mass index, history of tuberculosis (TB) treatment, bilateral lung lesions, and pre or extensively drug-resistant TB were significantly associated with treatment failure. Interestingly, the administration of bedaquiline or delamanid over 1 month was significantly associated with successful treatment (odds ratio, 5.939; 95\% confidence interval, 1.680-20.991; $\mathrm{p}<0.05)^{1}$. In a large cohort by Franke et al. ${ }^{2}$, $63 \%$ of the MDR-TB patients using bedaquiline, delamanid, or both experienced culture conversion within 6 months after the initiation of these drugs. Patients with human immunodeficiency virus (HIV) co-infection, high initial sputum smears, and cavitary lung disease had lower conversion rates than those without these risks. In our country, Indonesia, either bedaquiline or delamanid is used for 6 months if the patient is intolerant, contraindicated, or resistant to a fluoroquinolone

\footnotetext{
Address for correspondence: Oki Nugraha Putra, M.Clin.Pharm. Department of Clinical Pharmacy, Program Study of Pharmacy, Hang Tuah University, Arief Rahman Hakim 150, Surabaya 60111, East Java, Indonesia

Phone: 62-856-342-8984, Fax: 62-31-5946261

E-mail: oki.nugraha@hangtuah.ac.id

Received: Jul. 20, 2021

Revised: Jul. 25, 2021

Accepted: Aug. 1, 2021

Published online: Aug. 3, 2021

(c) It is identical to the Creative Commons Attribution Non-Commercial License (http://creativecommons.org/licenses/by-nc/4.0/).
}

or second-line injectable antituberculosis drugs. Fortunately, bedaquiline has been listed in the national program as a part of MDR-TB therapy in Indonesia, whereas delamanid has not $^{3}$. However, studies on the efficacy and safety of bedaquiline for MDR-TB management in Indonesia are very limited. Although bedaquiline is well-tolerated, we should fully consider before administering it. The serious adverse effect of this drug, Frederica-corrected (QTcF) prolongation, should be closely monitored by the pulmonologist and pharmacist ${ }^{4}$. In Indonesia, a study by Soeroto et al. ${ }^{5}$, reported that out of 492 MDR-TB patients, $50 \%$ of them were successfully treated. Culture conversion of sputum at less than two months was significantly more likely (2.79 times) to indicate successful MDR-TB treatment ${ }^{5}$. At the same time, chronic kidney disease, HIV, and cavitary lesion were risk factors of more prolonged treatment. Unfortunately, bedaquiline was not reported in that study ${ }^{5}$. Although bedaquiline or delanamid had beneficial effects in treating MDR-TB patients, other factors that may inhibit sputum conversion or prolong the duration of therapy should be considered while periodically supervising the side effects.

\section{Authors' Contributions}

Conceptualization: Putra ON, Hidayatullah AYN. Writing - original draft preparation: Putra ON, Hidayatullah AYN. Approval of final manuscript: all authors.

\section{Conflicts of Interest}

The authors declare no conflicts of interest regarding this study.

\section{References}

1. Kang Y, Jo EJ, Eom JS, Kim MH, Lee K, Kim KU, et al. Treatment outcomes of patients with multidrug-resistant tuberculosis: comparison of pre- and post-public-private mix periods. 
Tuberc Respir Dis 2021;84:74-83.

2. Franke MF, Khan P, Hewison C, Khan U, Huerga H, Seung KJ, et al. Culture conversion in patients treated with bedaquiline and/or delamanid: a prospective multicountry study. Am J Respir Crit Care Med 2021;203:111-9.

3. Ministry of Health of Indonesia Republic. Programmatic management of drug resistance tuberculosis 2011-2014 [Internet]. Jakarta: Ministry of Health of Indonesia Republic; 2016 [cited 2021 Jul 20]. Available from: https://www.who. int/docs/default-source/searo/indonesia/non-who-publica- tions/programmatic-management-of-drug-resistance-tb-inindonesia-2011-2014-bahasa.pdf?sfvrsn=aa2e3df1_2.

4. Guglielmetti L, Jaspard M, Le Du D, Lachatre M, MarigotOuttandy D, Bernard C, et al. Long-term outcome and safety of prolonged bedaquiline treatment for multidrug-resistant tuberculosis. Eur Respir J 2017;49:1601799.

5. Soeroto AY, Pratiwi C, Santoso P, Lestari BW. Factors affecting outcome of longer regimen multidrug-resistant tuberculosis treatment in West Java Indonesia: a retrospective cohort study. PLoS One 2021;16:e0246284. 